\title{
8 Healing Our Relationship with Gaia through a New Thrivability Paradigm
}

\author{
Anneloes Smitsman \\ EARTHwise Centre \\ Jude Currivan \\ WholeWorld-View
}

\section{CONTENTS}

Introduction.

The Cost of Conventional Progress.

Comparing Indigenous and Mechanistic Worldviews …………………………………...............91

What We Can Learn from the Infodynamics of Healthy Living Systems ......................................92

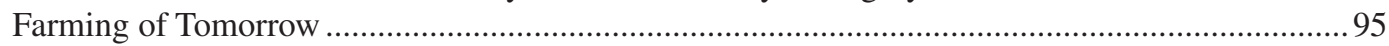

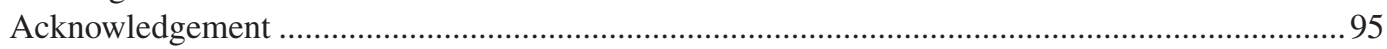

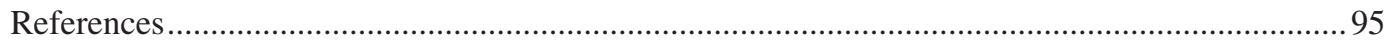

\section{INTRODUCTION}

Our worsening climate crisis, biodiversity loss and increasing societal challenges are all clear indicators that it is time for us to wise up and grow up. It is essential that we become conscious that the growth models that we have adopted for, and which shape, our developmental trajectories are not only unsustainable, but also imminently catastrophic. The resounding calls for a new paradigm with new norms are accelerating in strength around the world, even more so in the light of our current at the time of writing - coronavirus crisis. However, underlying each paradigm is a growth model, and unless this model is also transformed, the shift in paradigms will be limited and not generate new patterns for our collective thrivability.

The pursuit of growth in the economic domains has typically taken place via policies that only measure the quantitative aspects of growth, leading to extractive and unsustainable practices. In response, calls for degrowth are becoming more widely heard from sustainability movements. What is often missing in the discussion, however, is a deeper evaluation of what we mean by growth. Our usage of the word growth goes beyond the narrow conventional meaning that indicates an increase in size or quantity. We propose to emphasise the qualitative aspects of growth that are also developmental, as can be seen in the growth dynamics of living systems. Such growth often results in asymmetry, owing to structural changes between the variables that result from the new growth, which can temporarily perturb the balance of the system. Living systems are responsive, and it is precisely this shift in systemic balance due to growth changes that activates its learning and development. Living systems respond to emerging asymmetries through the formation of new organisational dynamics that enable the system to regulate and adjust to the changes. The formation of new balancing loops and informational flows is a process of systemic learning and development. 
Development over larger scales and longer time horizons can thus become an evolutionary growth process (Smitsman and Smitsman, 2020).

Our mainstream growth models have a tendency to focus only on the quantitative dimensions of growth, based on a mechanistic and dualistic worldview of the reality of life and the process of evolution. Instead of seeing life as a unified, interdependent and interconnected reality, life is perceived in a dualistic manner in which the external and internal are regarded as separate realities, and where the world is seen in terms of random events of separate particles. This mechanistic worldview also has a tendency to create extractive degenerative growth dynamics and constantly polarised, winlose divisions, which have brought not only us but also millions of other species, and even possibly the entire biosphere of Gaia, to the brink of extinction.

Over the last 50years, we have reduced biodiversity by half (IPCC, 2018; WWF, 2018). The anthropogenic damage to our planetary ecosystems, biodiversity resilience and climate systems extensively evidences that we are triggering the sixth mass extinction event in our planet's history (Meyer, 2019). The recent renaming of our age from the Holocene to the Anthropocene (Zalasiewicz et al., 2016), due to the irreversible human impacts on the geosphere and biosphere of our planet, indicates the urgency for seriously examining how to change our societal models (Bauer and Ellis, 2018).

In order to transform our growth and development models, and our mechanistic, separatist systems, we first need to become aware of and address our dualistic relationship with food and the ecology of life (Haukeland, 2013; Smitsman et al., 2019). The concept of sustainable development was initially adopted to address the impacts of these mechanistic systems, with the Brundtland Commission of 1987 coining the term and defining sustainable development as development that meets the needs of the present without compromising the ability of future generations to meet their own needs (Brundtland et al., 1987: 1). Through the years that followed, the concept of sustainable development expanded to include the safeguarding of the Earth's life-support systems on which the welfare of current and future generations depends (Griggs et al., 2013). Whilst this focus on safeguarding is important, it does not invite people to participate in a transformational change process that invokes their own evolutionary development.

We therefore offer the concept of thrivability, or our ability to thrive, as the transformational change process that invites people into a generative and evolutionary model that is both life-centred and future-oriented. To better understand what we mean by thrivability, we offer the following definition by Anneloes Smitsman, based on her $\mathrm{PhD}$ research on this topic:

Thrivability is the Life-intrinsic developmental potential for our self actualizing evolutionary growth. Thrivability as a developmental potential unfolds through an ecosystemic evolutionary learning process. Through this process we develop the future creative capabilities, awareness, and love to enact and embody the actualization of the thrivability potentials within the worlds and systems of which we form part. Embodied, these potentialities become possibilities for further growth and development in a way that is Life generative and creates conditions for each of us, and Life as a whole, to thrive.

Anneloes Smitsman (2019: 37)

A thrivability growth model, as will be explained further in greater detail, seeks to safeguard and strengthen the vital conditions of life that should never be sacrificed in the pursuit of food and resource development. With a broader focus, thrivability also invites us to explore the conditions and qualities of food cultivation systems and consumption patterns that honour and support our reciprocity, mutuality and inter-being with Gaia and the larger ecology of life.

\section{THE COST OF CONVENTIONAL PROGRESS}

When considered from an ecological whole-system perspective, the question 'what are progress and success?' provides a very different focus and narrative compared to how it continues to be defined by our mainstream economic, political and educational systems (Brewer and Smitsman, 
2018; Smitsman, 2019; Wahl, 2016). When we look at living systems, the feedback and feedforward informational loops support the overall thrivability of the whole system in a way that is both collaborative and actualising of consciousness; i.e., it is evolutionary coherent and developmental (Capra and Luisi, 2014; Laszlo and Laszlo, 2016). This is in stark contrast to many of our current societal systems where their progress, development and success come at a huge cost to its members and the environments from which it draws its resources (Scharmer and Kaufer, 2013; Korten, 2015). This cost is still not accounted for, even though international frameworks such as the Global Reporting Initiative (GRI) and Integrated Reporting (IR) are making it possible to broaden the capitalist model and report not only on the financial impacts of businesses but also their impacts on the environment and society (Hutchins, 2019).

Underlying these mechanistic systems that create more deficiencies than prosperity is a growth model that is completely out of sync with life. Unfortunately, many of our modern food cultivation methods are part of this vicious cycle (Haukeland, 2013). Research on modern farming practices is increasingly being linked to the progressive incidence and prevalence of systemic and autoimmune diseases of people and animals, as well as to contamination and degradation of the land (Sandifer et al., 2015). The current coronavirus crisis emphasises this even further, calling for a drastic review of food cultivation approaches as well as our livestock practices (see Van der Poel, 2020). To better understand why this growth model has turned so destructive, we will first explore its underlying worldviews and developmental processes.

\section{COMPARING INDIGENOUS AND MECHANISTIC WORLDVIEWS}

To better understand the development of mechanistic worldviews and practices, we offer some key reflections from other worldviews that are founded on a unity view of life and our relationship within the natural world. Such worldviews can still be found in the cosmologies and practices of many indigenous communities (Jacobs, 2016; Lane, 2019a; Randall, 2007; Smitsman et al., 2019), where reciprocity and co-dependency are regarded as guiding principles and which take great care to safeguard and honour these reciprocal relationships with the natural systems from which food resources are extracted (Lane, 2019b; Sanchez, 2017).

What we can learn from such indigenous worldviews is the evolutionary perspective of life (Lane et al., 2019). The health and thrivability of our ecosystems depend on the fine-tuning and intricate regulation of complex interdependencies that are nested holarchically - as holons within larger holons (Sahtouris, 2000). The term holarchy was coined by philosopher Arthur Koestler to describe how each whole thing within nature is a holon, a whole made of its own parts, yet itself part of a larger whole (Koestler, 1967). Holarchy also describes behaviour that is partly a function of individual nature and partly a function of the nature of the embedding system (Smitsman, 2019), and contrasts with growth models that developed from mechanistic dualistic worldviews which have hierarchical modes of organisation.

Such mechanistic growth models originate from societal changes that started about 5,000 years ago, when warlike kingdoms or empires started to develop (see Sahtouris, 2000). This period is characterised by aggressive policies for domination and control, driven by zero-sum game, winlose, competitive dynamics. Empire dynamics still dominate today through geopolitical shifts to the empire of corporations (see Sahtouris and Smitsman, 2019).

The modern dominant conception of progress and development originates from the empire dynamics and its mechanistic worldviews (Smitsman et al., 2019). Restoring a wholeworld-view ${ }^{1}$ is crucial to see the full picture and take responsibility for the impacts of the growth and prosperity models that we employ today for our societal development. No form of progress can be justified if this entails the

\footnotetext{
${ }^{1}$ The term wholeworld-view is used to differentiate its wholistic understanding of the wholeworld from otherwise fragmented worldviews.
} 
widespread destruction of our planet and the future conditions of our collective thrivability. Cosmologist Jude Currivan describes this emerging wholeworld-view in the following way:

While retaining the uniqueness of our personal, microcosmic expressions of consciousness, this wholeworld-view embraces the meso-cosm of our collective human experience and the macrocosm of our entire Universe, existing as a finite expression of the infinity and eternity of cosmic mind. When fully realized, such a view of the world does away with the conflictual interactions of duality perception, empowers mitigation of selfishness, and enhances cooperation and altruism, not only with each other but with all life as well.

Jude Currivan (2017: 229)

Another fundamental quality of many indigenous worldviews is the emphasis on gratitude for life itself. In all environments, whether abundant or scarce of resources, the expression of gratitude for honouring our reciprocity with nature is a cornerstone in many indigenous communities. For example, in the Quechua language of Peru, the word ayni embodies this, offering back to Mother Earth, Pacha Mama, in appreciation of what she offers us with such benevolence. The Q'ero shamans in Peru, whose small communities eluded the Spanish invaders over five centuries ago by escaping to the highest and most challenging reaches of the mountains, continue to live by principles of gratitude and honouring reciprocity.

This focus on gratitude and reciprocity can also be found in the indigenous landscapes of the United Kingdom. For example, excavations at Avebury in England, which has been standing as a monument for over 6,000 years, revealed an ancient offering. This offering, $2 \mathrm{ft}$ deep into the chalk bedrock from which flints were extracted, consisted of carefully placed, knapped flint implements and animal bones over 5,000 years old. This suggested to the archaeologists who found it that whoever had extracted the flint had made the offering in gratitude for its valued provision (Currivan, 2004).

Many indigenous traditions, both ancient and contemporary, have a wholistic worldview which accepts and honours the existence of multidimensional realms. From the beings known as huldufolk to Icelanders, to the kami of Japan, the apukuna mountain spirits of South America and the other and many names of elemental, devic and angelic entities around the world, such encounters are as old as humanity itself. Contemporary conscious communities such as the Findhorn Foundation in Scotland, founded in 1962, also commune with such realms as natural, everyday, realities. In many indigenous traditions, the honouring of these spirits and deities is regarded as an integral responsibility of growing and consuming food resources. Such realms appear invisible for those who have not developed their full or extra sensory capacities (Baring, 2015; Laszlo and Currivan, 2008).

The impact of our mechanistic worldviews is also apparent in the loss of a sense of the sacred. Land has become a commodity, rather than a living entity with intrinsic rights. Sacred sites are now tourist attractions, and mechanistic industrial farming practices have replaced indigenous ones around the world, which in the Amazon have damaged the rich black Terra Preta soils (Cornell University, 2019; Gibbons, 2019).

One of the first actions of adopting a thrivability paradigm would be a transformation of our current food industry and industrial farming practices. Such a transformation requires a deep understanding of the informational dynamics of healthy living systems, and how to implement this knowledge into design practices for a thrivability-based developmental trajectory. We will unpack those infodynamics in the following section.

\section{WHAT WE CAN LEARN FROM THE INFODYNAMICS OF HEALTHY LIVING SYSTEMS}

Thrivability sciences emerge as part of a new twenty-first-century paradigm whereby 'things' are in reality interdependent informational dynamics (infodynamics) within an integral living whole (Bateson, 2016; Laszlo and Laszlo, 2016; Smitsman, 2019). In this new paradigm, scientific laws are 
no longer viewed as mechanistic rules regarding the interaction patterns of particles, but rather are redefined and expanded in terms of informational content, coding and processes (Currivan, 2017: 6). This is being revealed at all scales of existence and across many fields of scientific research (Currivan, 2017; Smitsman and Currivan, 2019).

The science of infodynamics has previously been described as the study of the accumulation of informational constraints during system development (see Salthe, 2001). Jude Currivan has taken this study further to reinterpret the first two laws of thermodynamics as laws of infodynamics, for a better understanding how our universe evolves as a holographically informed wholeness, where its three-dimensional appearance is actually a holographic projection from the two-dimensional boundary of space (Currivan, 2017; Smitsman and Currivan, 2019). The science of infodynamics focuses on changes and impacts of meaningful in-formational ${ }^{2}$ patterns and content in living systems. Based on a universal 'alphabet' of the 1s and 0s of digitised information, it reveals how implicit cosmological dimensions underlie our manifest physical world and meaningfully combine these to in-form the forms of complex and living systems. It reveals that our physical world is a semiotically informational world and dissolves the dualistic notion that matter and energy are different. The concept of information is more fundamental than energy-matter and space-time and expresses in complementary ways as emergent phenomena of our universe. The science of infodynamics reveals, therefore, how from non-physical causative realms - the infinity and eternity of cosmic mind in Einstein's terminology - a finite universe is created that exists and evolves as a fundamentally interconnected coherent and unified entity (Currivan, 2019: 3).

The study of infodynamics also helps us to deepen our understanding of life as a generative field of possibilities (Sahtouris, 2000, 2013). By studying the infodynamics of life, we can learn how to apply this to the design of generative human systems that are evolutionary coherent and cosmologically informed. For example, this is currently applied to the world design of new economic and educational systems based on the cosmological principles of living systems (see Smitsman and Thurm, 2020; Smitsman and Houston, 2021). Accordingly, we can develop a generative wholeworld-view for guiding the evolutionary development of our world and future (Smitsman, 2019). When we shift our focus to generativity, and not mere sustainability, we start to design our worlds with the cosmological intelligence of life. Hence, our proposed focus on thrivability, as earlier explained in this chapter, as a generative future-creating process.

The study of infodynamics further opens a new, non-dualistic way of looking at causality. Life is a complex system of various interdependent, holarchically nested feedback and feedforward informational dynamics and flows. These flows reveal how we each are an infodynamic pattern within an evolutionary coherent and informing universe that affords possibilities for self-reflection and self-awareness and so allows us to become conscious of our evolution as the infodynamics for evolution (Smitsman et al., 2018). The study of infodynamics shows us how consciousness can emerge as an intrinsic quality of life and our universe, where consciousness is not something we have, but is what we and the wholeworld are (Currivan, 2017).

This dynamic informational flowing also forms the very conditions for evolutionary learning and development. Evolutionary learning cannot take place without, on the one hand, infodynamic flows that are generated by our activities that are interplaying within the larger whole called life and, on the other hand, the capacity to attune, adjust and respond to these flows (Fogel, 1993, Smitsman, 1997; Smitsman and Smitsman, 2020).

When we now apply this understanding to food cultivation and consumption within the growing field of agroecology, it enables us to deepen our understanding of what is implied by terms such as integrated farming. Words such as integrated and integral imply a multi- and inter-dimensional approach that requires knowledge and understanding of infodynamics. When we grow and consume

\footnotetext{
2 'Inform' and 'information' are sometimes written in this chapter as 'in-form' and 'in-formation' to emphasize how this type of cosmological information plays a key role in the formation and manifestation of our physical world.
} 
food, we also create specific informational patterns, and not all of those patterns are conducive for our thrivability and planetary health.

Owing to their lack of reciprocity with the healthy patterns of planetary ecosystems, food produced through systems that inhabit diseased information patterns also produces informational disease patterns that we in turn consume and propagate (Sahtouris, 2013). This gives a whole new meaning to the saying that you are what you eat. This understanding of health and disease as specific informational patterns is starting to emerge in the field of holistic medicine (Laszlo, 2017).

In order to better understand which infodynamics to apply for healthy and ecological food cultivation, we first need to understand the infodynamics of thrivable living systems. Living systems, compared to mechanistically created human systems, emerge from and generate healthy and regenerative infodynamic patterns due to the direct resonance and in-tunement with the cosmological intelligence of life.

Currivan's book and research demonstrate that when we reinterpret the first two laws of thermodynamics as laws of infodynamics, we start to see how the universe's informational content increases and diversifies as it spatially expands over time. This gives rise to growing complexity and evolutionary coherence (Currivan, 2017). Understanding evolutionary complexity is essential if we are to address complex issues such as runaway climate change, as indicative of systemic barriers that emerge from harmful complexity and degenerative growth patterns (see Smitsman, 2019).

The cosmological insights about the infodynamics of living systems through this chapter transform our understanding of reality itself - and turn the perception of a material, separate and essentially meaningless world on its head. Our beliefs drive our behaviours, and a wholeworld-view has the potential to empower transformational social change, including our behaviour towards our planetary home.

We will now apply some of these key points to evolutionary systems' design, which can also be applied to the design of evolutionary farming systems and practices. Anneloes Smitsman's PhD dissertation summarises the infodynamics of thrivable living systems as falling into five categories (adopted from Smitsman, 2019: 436):

1. Embodied Informational Wholeness That Is Holographically Distributed: Wholeness is a fundamental organisational principle of living systems, which cannot be understood by merely studying the parts of systems (Capra and Luisi, 2014). Thrivable living systems embody the systemic informational wholeness of life in their in-formation, organisation and behaviour. Informational wholeness in living systems gives rise to diversification (variability) that remains evolutionary coherent and unified (integrated) at deeper levels of the system (Smitsman and Currivan, 2019). When living systems grow more complex, their consciousness-actualising capacity also increases (Sahtouris, 2013). This embodying capacity is incredibly important from a developmental perspective of how consciousness as potentiality becomes aware through actualisation, from undifferentiated to differentiated awareness and back (Smitsman and Smitsman, 2020).

2. Future Creative Attractors: The future creative capacity of a living system is based on its capacity for renewal through its evolutionary development. The term 'future creative' also refers to a creative process that generates new patterns and new possibilities, i.e. new futures. In living systems, such a future creative process emerges from its evolutionary learning and development capacity. Evolutionary learning and development requires specific systemic attractors, affordances and sensory organs that combined make it possible to explore the infodynamics of the system's activities for new goals and purposes. Accordingly, living systems develop the sensory and attuning capabilities for adjusting their patterns and structures in a way that enables their further evolutionary development. The possibility space of a living system, its future potential, is precisely what acts as the attractor towards this developmental learning process (see Smitsman and Smitsman, 2020). 
3. Consciousness-Actualising Affordances: The evolutionary coherent complexity of living systems acts as affordance for consciousness to actualise, through developing self-awareness at various scales of being and inter-being. If a system does not afford the emergence and development of awareness, and does not afford the actualisation of consciousness, it is not a thrivability system.

4. Holarchic Complex Developmental Patterns: All living systems are complex developmental systems that generate holarchic patterns. A holarchic pattern is an organisational pattern whereby holons (wholes) are nested within larger holons (wholes) (Koestler, 1967). Holarchic patterns of complexity are generative, dynamic and evolutionary coherent. This is in contrast to hierarchic patterns that are degenerative, rigid and divisive. Information distribution in holarchic systems can be accessed at any level of the system due to its holographic nature and is attracted to the realisation of greater wholeness (Smitsman and Smitsman, 2020).

5. Evolutionary Coherent Behaviours: This is one of the most important qualities of thrivability systems; behaviour is sourced from the embedded informational wholeness and holographically distributed in a non-localised manner through the entire system. Accordingly, at any level of the system, the parts of the system can remain sourced from wholeness and informed by unity whilst diversification and growing complexity remains in dynamic place. This is the key to evolutionary coherence. This has also been referred to as the unity in diversity principle. Humanity is yet to master this evolutionary coherence in its behavioural patterns.

By learning from the behaviours of living systems and embedding those fractal potentialities in the design of our societal systems and interactions, we might start to understand how to systemically design for thrivability.

\section{FARMING OF TOMORROW}

The study of the infodynamics of healthy living systems, in this chapter also referred to as thrivability systems, provides guidelines for developing the agroecological farming systems of tomorrow. Indigenous science and practice has shown us the importance of including the infodynamics of living systems. If agroecological farming is to become truly wholistic in its practice, then it also requires inclusion of the non-local and multiple dimensions that inform growth in the finite, space-time-bound, local dimensions of our world.

Our current multifaceted global crisis offers an opportunity to enter into a conscious, healing and evolutionary relationship with Gaia. When we start to grow and cultivate our food from a sense of unity with all of life, and honour the integrity of our planetary ecosystems, a new thrivability model can emerge based on a fundamentally different relationship with food, resource cultivation, the land, each other and the larger ecology of life. Through this chapter, we hope to have inspired a deeper envisioning and regeneration of a healed and whole relationship with Gaia, the larger ecology of life and the wholeworld.

\section{ACKNOWLEDGEMENT}

We thank Dr Meredith Lowry for her valuable contribution.

\section{REFERENCES}

Baring, A. (2015) The Dream of the Cosmos: A Quest for the Soul. West Melbury: Archive Publishing. Bateson, N. (2016) Small Arcs of Larger Circles: Framing through Other Patterns. Axminster: Triarchy Press. Bauer, M. and Ellis, E.C. (2018) The Anthropocene divide: Obscuring understanding of social-environmental change. Current Anthropology 59(2). DOI: 10.1086/697198. 
Brewer, J. and Smitsman, A. (2018) Into the heart of systems change with Nora Bateson. EARTHwise Centre. https://youtu.be/QuA42Q_Ztto (accessed June 14th 2019).

Brundtland, G. et al. (1987) Our Common Future: Report of the 1987 World Commission on Environment and Development. Oxford: Oxford University Press.

Capra, F. and Luisi, P.L. (2014) The Systems View of Life: A Unifying Vision. New York: Cambridge University Press.

Cornell University (2019) Terra Preta de Indio. https://bit.ly/1SURQ9I (accessed September 12th 2019).

Currivan, J. (2004) Walking between worlds: Cosmology embodied in the landscape of Neolithic and Early Bronze Age Britain. PhD Dissertation. Reading: University of Reading.

Currivan, J. (2017) The Cosmic Hologram: In-formation at the Center of Creation. Rochester, Vermont: Inner Traditions/Bear and Company.

Currivan, J. (2019) A New INSCIght of INformational SCIence. www.judecurrivan.com (accessed August 23rd 2019)

Fogel, A. (1993) Developing through Relationships: Origins of Communication, Self and Culture. Chicago, IL: University of Chicago Press.

Gibbens, S. (2019) The Amazon is burning at record rates_-and deforestation is to blame. National Geographic, August 21, 2019. https://on.natgeo.com/2MsH1Pv (accessed September 15th 2019).

Griggs, D., Stafford-Smith, M., Gaffney, O., Rockström, J., Öhman, M.C., Shyamsundar, P., Steffen, W., Glaser, G., Kanie, N., and Noble, I. (2013) Sustainable development goals for people and planet. Nature, 495, 305-307.

Haukeland, P.I. (2013) Homo consumens, needless consumption and sources of transformation. Proceedings of Transformation in a Changing Climate, 19-21 June 2013, Oslo, Norway. University of Oslo. Interactive, pp. 89-96.

Hutchins, G. (2019) Natural business for a world that's waking up. The Nature of Business. https://bit.ly/ 2xhdBtZ (accessed June 30th 2019).

IPCC. (2018) Summary for policymakers. In Masson-Delmotte, V. et al., (eds), Global Warming of $1.5^{\circ} \mathrm{C}$ : An IPCC Special Report on the Impacts of Global Warming of $1.5^{\circ} \mathrm{C}$ above Pre-Industrial Levels and Related Global Greenhouse Gas Emission Pathways (32 pp.). Geneva: World Meteorological Organization.

Jacobs, D.T. (Four Arrows) (2016) Point of Departure: Returning to Our More Authentic Worldview for Education and Survival. Charlotte, NC: Information Age Publishing, Inc.

Koestler, A. (1967) The Ghost in the Machine (1990 reprint ed.). London: Hutchinson (Penguin Group).

Korten, D. (2015) From serving money to serving life: A sacred story for our time. Online lecture. https:// youtu.be/Aad6E9TgqS0.

Lane, P. (2019a) International treaty to protect and restore mother earth. The Four Worlds International Institute. https://bit.ly/2ZiGC6T (accessed September 1st 2020).

Lane, P. (2019b) Sixteen indigenous guiding principles for co-creating a sustainable, harmonious, prosperous world. https://bit.ly/32b5IV5 (accessed June 4th 2019).

Lane, P., Ramer, J., Longboat, K.D., and Moldow, D. (2019) Prophecies, dynamic change, and a new global civilization: 2020-2030-2050. https://goo.gl/Lomwav (accessed March 3rd 2019).

Laszlo, E. (ed.) (2017) Beyond Fear and Rage: New Light from the Frontiers of Science and Spirituality. Cardiff, CA: Waterfront Digital Press.

Laszlo, E. and Currivan, J. (2008) CosMos. Carlsbad, CA: Hay House.

Laszlo, E. with Laszlo, A. (2016) What Is Reality? The New Map of Cosmos and Consciousness. New York: SelectBooks, Inc.

Meyer, R. (2019) The cataclysmic break that (maybe) occurred in 1950 sixty-nine years ago, a new geological era may have begun on Earth. The Atlantic, April 2019. https://bit.ly/2UY3oA4 (accessed August 8th 2019).

Randall, B. (2007) Kanyini. Resurgence and Ecologist 2(1): 243.

Sahtouris, E. (2000) EARTHDANCE: Living Systems in Evolution. Bloomington, IN: iUniverse.

Sahtouris, E. (2013) Gaia's Dance: The Story of Earth and Us: A Children's Book for Grownups. Kindle Edition.

Sahtouris, E. and Smitsman, A. (2019) Into the heart of systems change with Dr Elisabet Sahtouris. EARTHwise Centre YouTube Channel. https://youtu.be/jhSPsJQZe8E.

Salthe, S.N. (2001) What is infodynamics? In Ragsdell, G. and Wilby, J. (eds), Understanding Complexity (pp. 31-38). Boston, MA: Springer.

Sanchez, A. (2017) The Four Sacred Gifts: Indigenous Wisdom for Modern Times. New York: Atria/Enliven Books, Simon and Schuster. 
Sandifer, P.A., Sutton-Grier, A.E., and Ward, B.P. (2015) Exploring connections among nature, biodiversity, ecosystem services, and human health and well-being: Opportunities to enhance health and biodiversity conservation. Elsevier Ecosystem Services 12: 1-15.

Scharmer, O. and Kaufer, K. (2013) Leading from the Emerging Future: From Ego-System to Eco-System Economies. San Francisco, CA: Berrett-Koehler Publishers, Inc.

Smitsman, A.W. (1997) The development of tool use: Changing boundaries between organism and environment. In Dent-Read, C. and Zukow-Goldring, P. (eds), Evolving Explanations of Development: Ecological Approaches to Organism-Environment Systems (pp. 301-329). Washington, DC: American Psychological Association.

Smitsman, A. (2019) Into the heart of systems change. Doctoral dissertation. Maastricht: University of Maastricht, Maastricht Sustainability Institute.

Smitsman, A. and Currivan, J. (2019) Systemic transformation: Into the birth canal. Systems Research and Behavioral Science 36(4), 604-613. DOI: 10.1002/sres.2573.

Smitsman, A and Houston, J. (2021) Future humans: A spiritual science novel for our greatest transformation [forthcoming].

Smitsman, A. and Smitsman, A.W. (2020) The future-creative human: Exploring evolutionary learning. World Futures: The Journal of New Paradigm Research 76(4): 214-239.

Smitsman, A. and Thurm, R. (2020) The future normals webinar series. EARTHwise Centre and r3.0, https:// bit.ly/316lphJ.

Smitsman, A., Laszlo, A., and Barnes, K. (2018) Attracting our future into being: The syntony quest. World Futures: The Journal of New Paradigm Research 75(1): 1-22.

Smitsman, A., Martens, P., and Laszlo, A. (2019) The polarization effect: Healing our worldviews. Systema 7(1): 1-23.

Van der Poel, W. (2020). Staying ahead of viruses. Online article, Wageningen University. https://weblog.wur. eu/spotlight/staying-ahead-of-viruses/.

Wahl, D.C. (2016) Designing Regenerative Cultures. Axminster: Triarchy Press.

WWF (2018) The Living Planet Report 2018: Aiming Higher. Gland: WWF International.

Zalasiewicz, J., Summerhayes, C., Barnosky, A.D., Poirier, C., Gałuszka, A., Cearreta, A., Edgeworth, M., Ellis, E.C., Ellis, M., Jeandel, C., Leinfelder, R., McNeill, J.R., de Richter, D.B., Steffen, W., Syvitski, J., Vidas, D., Wagreich. M., Williams, M., Zhisheng, A., Grinevald, J., Odada, E., Oreskes, N. and Wolfe, A.P. (2016) The Anthropocene is functionally and stratigraphically distinct from the Holocene. Science 351(6269): $\operatorname{aad} 2622$. 